\title{
Non-secretion of AFP and neutrophil Iymphocyte ratio as predictors for survival in hepatocellular carcinoma patients treated with sorafenib: a large UK cohort
}

\author{
Mehran Afshar ${ }^{1}$, Peter Fletcher ${ }^{2}$, Antonio D Bardoli ${ }^{3}$, Yuk Ting Ma ${ }^{4, *}$ and Pankaj \\ Punia ${ }^{5, *}$ \\ ${ }^{1}$ Oncology, St George's University Hospitals NHS Foundation Trust, London, UK \\ ${ }^{2}$ Cancer Research UK Clinical Trials Unit, Birmingham, UK \\ ${ }^{3}$ College of Medical and Dental Sciences, University of Birmingham, Birmingham, UK \\ ${ }^{4}$ Institute of Immunology and Immunotherapy, University of Birmingham, Birmingham, UK \\ ${ }^{5}$ Oncology, Queen Elizabeth Hospital Birmingham, Birmingham, UK \\ *These authors contributed equally to this work \\ Correspondence to: Pankaj Punia, email: Pankaj.Punia@uhb.nhs.uk \\ Keywords: neutrophil lymphocyte ratio (NLR); alpha-fetoprotein (AFP); hepatocellular carcinoma; sorafenib; survival \\ Received: July 31, $2017 \quad$ Accepted: February 27, $2018 \quad$ Published: March 30, 2018 \\ Copyright: Afshar et al. This is an open-access article distributed under the terms of the Creative Commons Attribution License 3.0 \\ (CC BY 3.0), which permits unrestricted use, distribution, and reproduction in any medium, provided the original author and source \\ are credited.
}

\section{ABSTRACT}

Background: Sorafenib is the current standard of care for patients with advanced or metastatic hepatocellular carcinoma. Currently no universally agreed model exists correlating the Neutrophil Lymphocyte ratio (NLR) and non-secretion of AFP with the survival of HCC patients treated with sorafenib.

Patients and Methods: We retrospectively analysed patient records with a confirmed diagnosis of HCC treated with sorafenib between April 2009 and March 2014. Survival analysis was performed using the Kaplan-Meier method and Cox regression.

Results: Patients separated into groups based on NLR ( $\leq 3$ or $>3)$, or AFP secretion profile $(<7 \mathrm{ng} / \mathrm{ml}$ or $\geq 7 \mathrm{ng} / \mathrm{ml}$ ) derived diverging Kaplan-Meier curves for overall survival (OS). The median OS in those with NLR $\leq 3.0$ was 9.0 months (95\% CI: 7.7-11.1 months) and in those with NLR >3.0 it was 6.0 months (95\% CI: 4.9-8.2 months) [HR 1.32 (95\% CI: 0.96-1.80)]. The median overall survival post sorafenib was higher in the "non-secretor" AFP group. OS for AFP <7 ng/ml was 10.0 months (95\% CI: 7.7-19.3 months) compared to AFP $\geq 7 \mathrm{ng} / \mathrm{ml:} 6.6$ months (95\% CI: 5.3-8.4 months) [HR 1.64 (95\% CI: 1.15-2.33)].

Conclusion: NLR and AFP non - secretion at diagnosis are potential significant prognosticators for overall survival from initiation of sorafenib.

\section{INTRODUCTION}

Hepatocellular carcinoma (HCC) is a highly aggressive malignancy representing the sixth most common cancer and the third leading global cause of cancer related deaths $[1,2]$. In the western world the incidence of HCC is still rising [1]. Unfortunately, the majority of patients present at an advanced, non-curative stage.
The Barcelona Clinic Liver Cancer (BCLC) algorithm is an accepted and validated staging system, providing a framework for the management of HCC [3]. Patients with good liver synthetic function and early stage tumour (BCLC 0, A) are eligible for curative treatment options whereas patients with poor liver function and performance status (BCLC D) are advised best supportive care. Patients within BCLC B and C category are eligible for palliative treatment options (loco-regional 
or systemic). Despite significant improvements in locoregional and targeted treatment, the long term outcome for patients with advanced HCC remains poor [2].

The 'SHARP' and 'Asia-Pacific' studies have established sorafenib as the current standard of care for patients with advanced HCC in the first line setting $[4,5]$. Sorafenib is an orally active multikinase inhibitor of Raf, Platelet-derived Growth Factor (PDGF) and Vascular Endothelial Growth Factor (VEGF) receptors [6]. A body of evidence exists for the wide heterogeneity of response to sorafenib, but robust prognosticators in this setting are lacking [7-10].

There is increasing evidence that cancer-related inflammation plays an important role in cancer development and progression, through upregulation of cytokines and inflammatory mediators [11]. This is especially the case in HCC which usually arises on a background of chronic hepatitis and cirrhosis. Indeed genomic studies of the adjacent non-neoplastic tissue in HCC following surgical resection have identified a proinflammatory gene signature that predicts late recurrence and poor survival [12]. The neutrophil-to-lymphocyte ratio (NLR) is one measure of the systemic inflammatory response with the advantage that it can be readily assessed through a peripheral blood test. An elevated NLR has been associated with a poorer overall survival in many solid tumours [13]. Three recent systematic reviews (the largest involving 20475 patients) have also demonstrated that NLR is a major prognostic factor in $\mathrm{HCC}$; a high baseline NLR was associated with adverse disease-free and/or overall survival in patients with HCC [14-16]. Furthermore, subgroup analyses showed that baseline NLR was prognostic of overall survival for all treatment options in HCC (with the exception of radiofrequency ablation), although the sorafenib group was made up of only two small retrospective studies with 102 and 68 patients respectively [16-18].

Alpha-fetoprotein (AFP) levels have also been investigated as a marker to predict the response of HCC patients after loco-regional treatment or systemic chemotherapy. AFP is a serum glycoprotein that was first identified nearly 50 years ago [19]. It is synthesised in high levels by the foetal yolk sac and foetal liver but its expression is then repressed shortly after birth. Reappearance of AFP in the circulation in adults is associated with chronic hepatitis and liver cirrhosis as well as malignancies such as HCC and gastrointestinal cancers of endodermal origin [20]. AFP is secreted into the blood of approximately $70 \%$ of all patients with HCC and higher levels have been found to be associated with a worse prognosis [21-25]. Consequently, AFP has been incorporated into many of the available scoring and staging systems for HCC. However $30-50 \%$ of patients with unresectable $\mathrm{HCC}$ do not have elevated AFP levels, representing a significant proportion of this group [26, 27]. Patients with low AFP are known to have better prognosis but apart from this, there is a paucity of data regarding prognostic biomarkers in this subgroup of patients.

In this large cohort study of 231 patients at an academic cancer centre in the UK, we aimed to correlate the response to sorafenib with NLR and non-secretion of AFP and assess their validity as prognostic biomarkers for HCC.

\section{RESULTS}

\section{Baseline characteristics}

A total of 231 patients were included in the preliminary notes review. 17 were excluded at first review for unconfirmed diagnosis of $\mathrm{HCC}$ or not receiving sorafenib. The remaining 214 selected patients consisted of $172(79 \%)$ males and 45 (21\%) females. (Table 1A).

The patients were stratified into two groups according to NLR: Low NLR group $<3(n=104)$ and high NLR group $>3(n=110)$. The two groups were generally well balanced for sex, age, Child-Pugh class (CP), portal vein invasion and previous treatments (in categories with more than a few patients), with the low NLR group having a slightly lower age profile. The low NLR group also had a lower AFP profile with more "non-secretors" (AFP $<7$ $\mathrm{ng} / \mathrm{ml})$ and fewer patients with high AFP (>400 ng/ml) than the high NLR group. There were more patients with hepatitis (B and C) and alcoholic liver disease (ALD) in the low NLR group.

We also stratified the patients by AFP secretion status. Non-secretors were defined as having an AFP of $<7$ $\mathrm{ng} / \mathrm{ml}(n=62)$ and secretors as having an AFP $>7 \mathrm{ng} / \mathrm{ml}$ $(n=152)$. We further analysed the baseline characteristics of these AFP secretor groups (Table 1B). Both groups were generally well balanced for age, CP class, aetiological factors for $\mathrm{HCC}$ and previous treatments, with the nonsecretor group having a slightly lower age profile. There was a marked imbalance between the two groups for sex with a much higher proportion of men in the non-secretor group. There were also more patients with portal vein invasion in the secretor group.

\section{Overall survival}

\section{NLR}

The median overall survival in those with NLR $\leq 3.0$ was 9.0 months (95\% CI: 7.7-11.1 months) and in those with NLR $>3.0$ it was 6.0 months (95\% CI: 4.9-8.2 months). (Figure 1). The hazard ratio of NLR $>3$ to NLR $\leq 3$ indicate that higher NLR is associated with shorter survival times (HR1.45 (95\% CI: 1.07, 1.95)). When adjusted for CP class, portal vein invasion and AFP the trend was still apparent (HR1.32 (95\% CI: 0.96, 1.80)). This statistical significance was lost when the NLR ratio 


\begin{tabular}{|c|c|c|c|c|}
\hline & & $\mathrm{NLR} \leq 3(n=104)$ & $\operatorname{NLR}>3(n=110)$ & All patients $(n=214)$ \\
\hline \multirow[t]{2}{*}{ Sex } & Male & $82(79 \%)$ & $88(80 \%)$ & $170(79 \%)$ \\
\hline & Female & $22(21 \%)$ & $22(20 \%)$ & $44(21 \%)$ \\
\hline \multirow[t]{4}{*}{ Age $(n=207)$} & Median (IQR) & $65(60,73)$ & $67(61,74)$ & $66(60,74)$ \\
\hline & Range & $14-86$ & $15-82$ & $14-86$ \\
\hline & $\leq 66$ & $56(55 \%)$ & $49(46 \%)$ & $105(51 \%)$ \\
\hline & $>66$ & $45(45 \%)$ & $57(54 \%)$ & $102(49 \%)$ \\
\hline \multirow[t]{3}{*}{ Child-Pugh } & A & $69(66 \%)$ & $71(65 \%)$ & $140(65 \%)$ \\
\hline & B & $33(32 \%)$ & $37(34 \%)$ & $70(33 \%)$ \\
\hline & $\mathrm{C}$ & $2(2 \%)$ & $2(2 \%)$ & $4(2 \%)$ \\
\hline \multirow[t]{3}{*}{ AFP } & $<7 \mathrm{ng} / \mathrm{ml}$ & $40(38 \%)$ & $22(20 \%)$ & $62(29 \%)$ \\
\hline & $\geq 7 \mathrm{ng} / \mathrm{ml}<400 \mathrm{ng} / \mathrm{mL}$ & $40(38 \%)$ & $42(38 \%)$ & $82(38 \%)$ \\
\hline & $\geq 400 \mathrm{ng} / \mathrm{ml}$ & $24(23 \%)$ & $46(42 \%)$ & $70(33 \%)$ \\
\hline \multirow[t]{2}{*}{ Portal vein invasion } & Yes & $68(65 \%)$ & $70(64 \%)$ & $138(64 \%)$ \\
\hline & No & $36(35 \%)$ & $40(36 \%)$ & $76(36 \%)$ \\
\hline \multirow[t]{6}{*}{ Aetiology } & ALD & $18(17 \%)$ & $12(11 \%)$ & $30(14 \%)$ \\
\hline & Hepatitis B & $11(11 \%)$ & $6(5 \%)$ & $17(8 \%)$ \\
\hline & Hepatitis C & $17(16 \%)$ & $7(6 \%)$ & $24(11 \%)$ \\
\hline & NASH & $8(8 \%)$ & $10(9 \%)$ & $18(8 \%)$ \\
\hline & Combination & $2(2 \%)$ & $10(9 \%)$ & $12(6 \%)$ \\
\hline & Unknown/other & $48(46 \%)$ & $65(59 \%)$ & $113(53 \%)$ \\
\hline \multirow[t]{4}{*}{ Previous treatment } & TACE & $24(23 \%)$ & $32(29 \%)$ & $56(26 \%)$ \\
\hline & RFA & $7(7 \%)$ & $1(1 \%)$ & $8(4 \%)$ \\
\hline & TACE \& RFA & $7(7 \%)$ & $1(1 \%)$ & $8(4 \%)$ \\
\hline & None & $66(63 \%)$ & $76(69 \%)$ & $142(66 \%)$ \\
\hline
\end{tabular}

was increased to 4 or 5 but HR trend was maintained. Loss of statistical significance in our cohort may be related to small sample size (Table 2).

A log-rank test comparing NLR $<3$ with NLR $\geq$ 3 found a statistically significant difference between the survival outcomes for the two groups: $(p=0.015)$. A log-rank test stratified by CP class, portal vein invasion and AFP level $(<7 \mathrm{ng} / \mathrm{ml})$ was marginally significant $(p$ $=0.055)$. We used backwards elimination method for significant variables.

\section{AFP}

The median overall survival post sorafenib was higher in the "non-secretor" AFP groups. OS for AFP $<7 \mathrm{ng} / \mathrm{ml}$ was 10.0 months (95\% CI: 7.7-19.3 months) compared to AFP $\geq 7 \mathrm{ng} / \mathrm{ml}$ : 6.6 months (95\% CI: $5.3-8.4$ months). (Figure 2). The non-secretors of AFP showed an unadjusted $\mathrm{HR}$ of 1.87 (95\% CI 1.3-2.6) and an adjusted HR of 1.64 (95\% CI: 1.2-2.3) for CP class, portal vein invasion, previous treatment.

A log-rank test comparing AFP $<7 \mathrm{ng} / \mathrm{ml}$ with $\mathrm{AFP}=$ $>7 \mathrm{ng} / \mathrm{ml}$ found a highly statistically significant difference between the survival outcomes for the two groups: ( $p=$ 0.0003). A log-rank test stratified by CP class, portal vein invasion and previous localised treatments (RFA/TACE) was also statistically significant $(p=0.0080)$.

\section{DISCUSSION}

Sorafenib was established as the first treatment to improve overall survival in patients with advanced HCC in $2008[4,5]$, yet to date, there remains no validated predictive or prognostic biomarker for its use. We show that NLR and non-secretion of AFP have potential to be prognostic biomarkers in this setting with the additional advantages of being readily available and inexpensive.

In this large single-centre cohort of consecutive patients treated with sorafenib, we observed that patients with an elevated pre-treatment NLR $(>3)$ have a significantly worse overall survival following treatment with sorafenib compared with patients with a NLR $\leq 3$. Our results are consistent with the emerging data in this area and adds to the evidence base; since we embarked on this study there are now three small retrospective studies and one large observational study that have all demonstrated 
Table 1B: Baseline Characteristics AFP secretors groups

\begin{tabular}{|c|c|c|c|c|}
\hline & & $\mathrm{AFP}<7 \mathrm{ng} / \mathrm{mL}(n=62)$ & $\mathrm{AFP} \geq 7 \mathrm{ng} / \mathrm{mL}(n=152)$ & All patients $(n=214)$ \\
\hline \multirow[t]{2}{*}{ Sex } & Male & $56(90 \%)$ & $114(75 \%)$ & $170(79 \%)$ \\
\hline & Female & $6(10 \%)$ & $38(25 \%)$ & $45(21 \%)$ \\
\hline \multirow{4}{*}{$\begin{array}{l}\text { Age } \\
(n=207)\end{array}$} & Median (IQR) & $64.5(55,71)$ & $67(61,75)$ & $66(60,74)$ \\
\hline & Range & $16-86$ & $14-84$ & $14-86$ \\
\hline & $\leq 66$ & $34(59 \%)$ & $71(48 \%)$ & $105(51 \%)$ \\
\hline & $>66$ & $24(41 \%)$ & $78(52 \%)$ & $102(49 \%)$ \\
\hline \multirow[t]{3}{*}{ Child-Pugh } & A & $40(65 \%)$ & $100(66 \%)$ & $140(65 \%)$ \\
\hline & B & $22(35 \%)$ & $48(32 \%)$ & $70(33 \%)$ \\
\hline & $\mathrm{C}$ & $0(0 \%)$ & $4(3 \%)$ & $4(2 \%)$ \\
\hline \multirow[t]{2}{*}{ NLR } & $\leq 3.0$ & $40(65 \%)$ & $64(42 \%)$ & $104(49 \%)$ \\
\hline & $>3.0$ & $22(35 \%)$ & $88(58 \%)$ & $110(51 \%)$ \\
\hline \multirow{2}{*}{$\begin{array}{l}\text { Portal vein } \\
\text { invasion }\end{array}$} & Yes & $13(21 \%)$ & $63(41 \%)$ & $76(36 \%)$ \\
\hline & No & $49(79 \%)$ & $89(59 \%)$ & $138(64 \%)$ \\
\hline \multirow[t]{6}{*}{ Aetiology } & ALD & $10(16 \%)$ & $20(13 \%)$ & $30(14 \%)$ \\
\hline & Hepatitis B & $4(6 \%)$ & $13(9 \%)$ & $17(8 \%)$ \\
\hline & Hepatitis C & $7(11 \%)$ & $17(11 \%)$ & $24(11 \%)$ \\
\hline & NASH & $6(10 \%)$ & $12(8 \%)$ & $18(8 \%)$ \\
\hline & Combination & $4(6 \%)$ & $8(5 \%)$ & $12(6 \%)$ \\
\hline & Unknown/other & $31(50 \%)$ & $82(54 \%)$ & $113(53 \%)$ \\
\hline \multirow{4}{*}{$\begin{array}{l}\text { Previous } \\
\text { treatment }\end{array}$} & TACE & $16(26 \%)$ & $40(26 \%)$ & $56(26 \%)$ \\
\hline & RFA & $4(6 \%)$ & $4(3 \%)$ & $8(4 \%)$ \\
\hline & TACE \& RFA & $4(6 \%)$ & $4(3 \%)$ & $8(4 \%)$ \\
\hline & None & $38(61 \%)$ & $104(68 \%)$ & $142(66 \%)$ \\
\hline
\end{tabular}

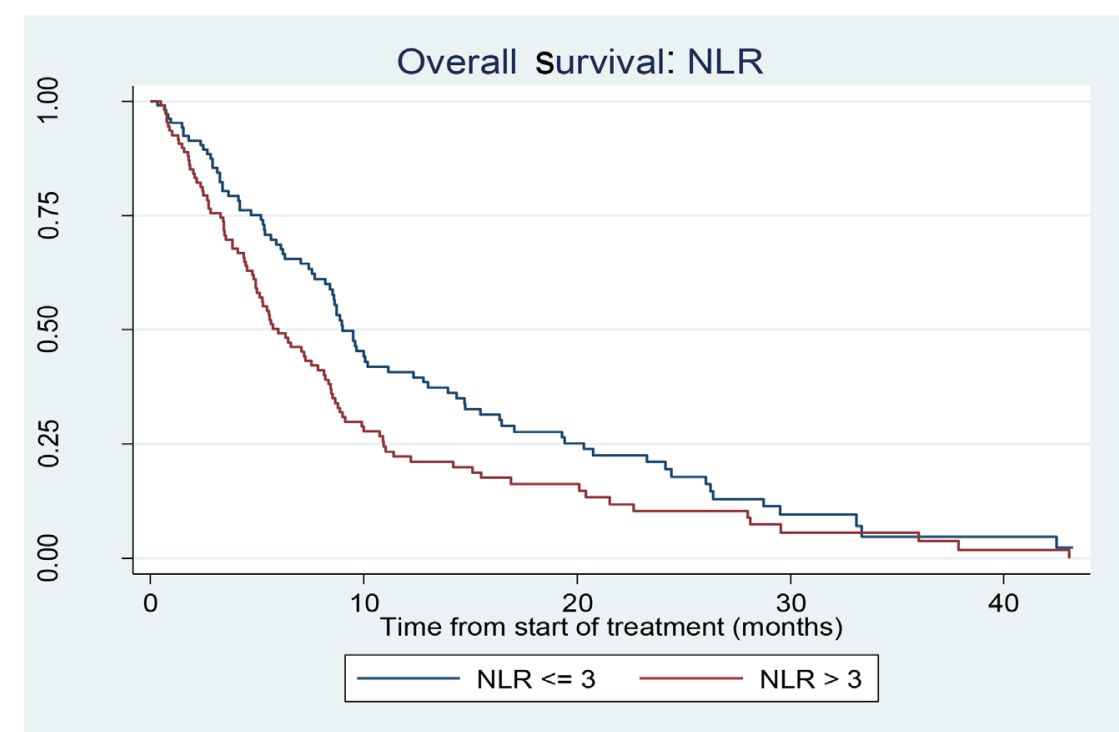

Figure 1: Kaplan Meier curve showing survival in patients with $N L R \leq 3$ versus NLR $>3$. 
Table 2: Overall Survival stratified by NLR

\begin{tabular}{lccc}
\hline & \multicolumn{2}{c}{ Unadjusted $(\boldsymbol{n}=\mathbf{2 1 4})$} & Adjusted $^{\mathbf{1}}(\boldsymbol{n}=\mathbf{2 1 4})$ \\
\hline NLR & Number (\%) in higher group & HR (95\% CI) & HR (95\% CI) ${ }^{\mathbf{3}}$ \\
$\mathbf{3}$ & $110(51 \%)$ & $1.45(1.07,1.95)$ & $1.32(0.96,1.80)$ \\
$\mathbf{4}$ & $62(29 \%)$ & $1.22(0.88,1.69)$ & $1.27(0.91,1.77)$ \\
$\mathbf{5}$ & $42(20 \%)$ & $1.47(1.01,2.13)$ & $1.39(0.95,2.04)$ \\
\hline
\end{tabular}

Adjusted for Child-Pugh class, portal vein invasion and $\ln (\mathrm{AFP})$.

that elevated pre-treatment NLR is associated with poorer TTP and/or overall survival following sorafenib treatment, after adjusting for clinical covariates [17, 18, 28, 29]. One major limitation of the existing studies is that all of the studies (including ours) have been observational and mostly retrospective in nature, and thus the prognostic ability of NLR still requires prospective evaluation.

During the writing of this manuscript, exploratory analyses from two prospective studies performed in patients with advanced HCC have been published: Personeni et al. analysed the prognostic value of NLR in patients treated in the ARQ 197-215 study, a randomised placebo-controlled study testing the MET inhibitor tivantinib in the second line setting for patients with advanced HCC [30]. Multivariate analysis revealed that baseline NLR was an independent prognostic biomarker in this setting; NLR $>3$ was associated with poorer survival (HR1.65; 95\% CI 1.05; 2.59; $p=0.03$ ) [30]. Bruix et al. conducted a pooled exploratory analysis from the 2 landmark placebo-controlled phase 3 studies (SHARP and Asia-Pacific) in an attempt to identify prognostic factors for OS and predictive factors of sorafenib benefit [31]. A high NLR ( $\leq$ vs $>$ median [3.1]) was a strong and independent prognostic factor for overall survival. Furthermore, the OS benefit of sorafenib was consistently observed in all subgroups but patients with a low NLR derived a greater OS benefit from sorafenib treatment (HR, 0.59 vs 0.84 ) [31]. Thus in advanced HCC the available literature now robustly supports NLR as an independent prognostic factor for survival in this group, independent of treatment allocation, in both the first line and second line setting.

Another important finding of our study is that patients who do not secrete AFP have a significantly improved OS. Although low AFP is known to be associated with better outcomes in $\mathrm{HCC}$ following surgical resection and liver transplantation, to our knowledge, this is the first time this has been reported for patients undergoing sorafenib treatment.

There is a paucity of research on patients with low AFP and HCC and in particular potential prognostic factors in this subgroup. In our study, we found no evidence that NLR ratio $<>3$ was associated with survival in the AFP non-secretor subgroup, however the numbers of patients contributing to this analysis was only small. However, a unique finding from our study is the association of low

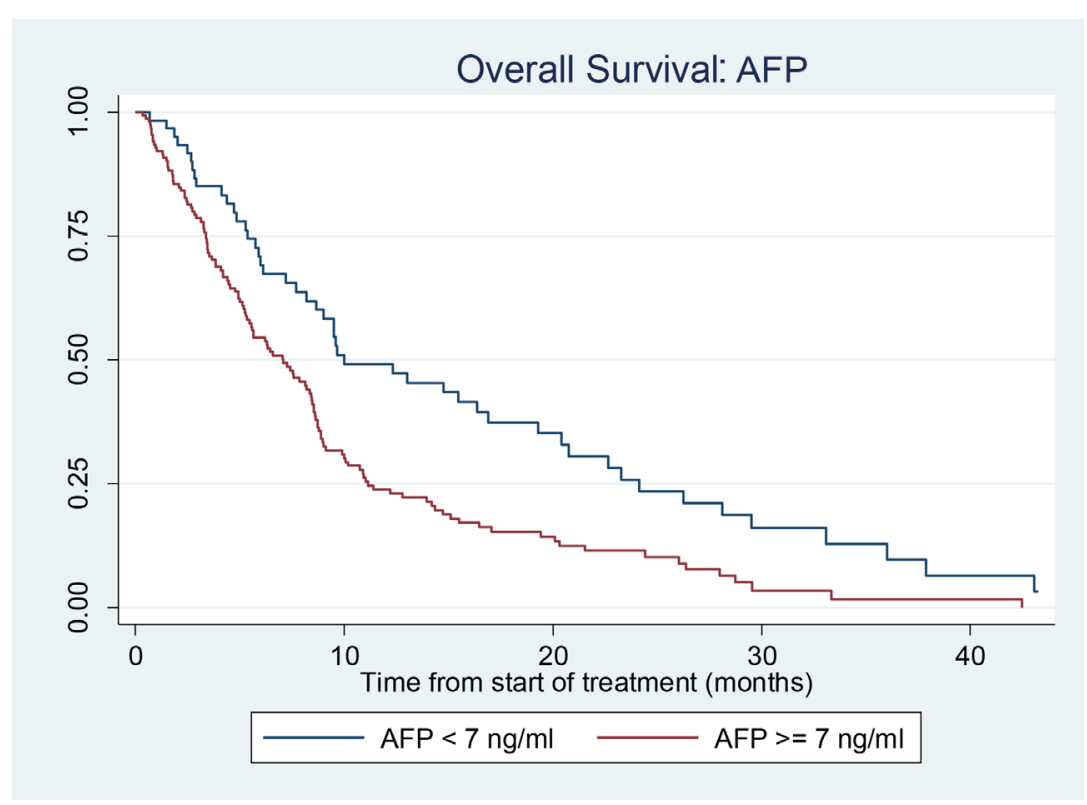

Figure 2: Kaplan Meier curve showing survival in patients with AFP $<7$ and AFP $\geq 7$. 
AFP with low NLR, with a much higher proportion of patients with low NLR in the AFP non-secretor group compared to the AFP secretors. This has not previously been reported. Whilst prospective validation of this finding is needed, this association may in part explain the better prognosis of patients with HCC who do not secrete AFP. Recent in vitro studies have demonstrated that tumourderived AFP can directly impair natural killer (NK) cell activation and viability [32], indirectly impair NK cell activity through suppression of dendritic cell function [33], and induce aberrant dendritic cell differentiation with consequential reduction in the secretion of inflammatory cytokines and chemokines and limited $\mathrm{T}$ cell activation $[34,35]$. Thus shifting the balance towards a high NLR in the presence of AFP.

There has only been one other study which has looked at prognostic biomarkers in the subset of patients with low AFP. Carr et al. demonstrated that serum gamma glutamyl transpeptidase (GGGT) levels correlated with survival in patients with unresectable HCC and low AFP [27]. As GGGT is also a readily available test, we recommend prospective evaluation of the combination of NLR and GGGT in patients with HCC and non-secretion of AFP.

Other prognostic biomarkers associated with sorafenib have also been investigated. In the the SHARP trial, Llovet et al. analysedplasma biomarkers- Ang2, bFGF,VEGF, sVEGFR-2,sVEGFR-3,HGF, s-c-KIT, IGF2 and Ras after 12 weeks of treatment with sorafenib [36]. This revealed that only Ang2 and VEGF were independent predictors of survival but none of the biomarkers were predictive of response to treatment [36]. Furthermore Masuda et al. recently reported that expression of high mobility group box 1 (HMGB1) at 4 weeks was an independent predictor of poor overall survival with sorafenib treatment $(P=0.001)$ [37]. However the costeffectiveness and availability of these markers in routine clinical practise are significant limitations. The advantage of NLR and AFP is that they are both inexpensive routine blood tests which are frequently used when planning HCC treatment.

In summary, we have shown that NLR and nonsecretion of AFP both have potential as prognostic biomarkers in patients with advanced HCC treated with sorafenib. Further prospective validation of our findings is required, in particular the association of low AFP and low NLR, but if these findings are validated then these may provide clinicians with inexpensive and routinely available biomarkers to better help select patients for future treatment and clinical trials.

\section{PATIENTS AND METHODS}

All patients with a confirmed diagnosis of $\mathrm{HCC}$, either histologically or radiologically as per internationally accepted American Association for Study of Liver
Diseases (AASLD) criteria, who commenced treatment with sorafenib at our centre between April 2009 and March 2014 were included in this analysis.

Electronic patient records were reviewed and variables including demographics, haematological and biochemical laboratory results, radiological data and survival outcomes were collected. Survival analysis was performed using the Kaplan-Meier method, Cox regression and log-rank tests. All analyses were performed in Stata 14.

\section{Abbreviations}

Hepatocellular carcinoma (HCC), Neutrophil Lymphocyte ratio (NLR), Alpha-fetoprotein (AFP), overall survival (OS), confidence intervals (CI), Barcelona Clinic Liver Cancer Algorithm (BCLC), platelet derived growth factor (PDGF), vascular endothelial growth factor (VEGF), American Association for the study of Liver Disease (AASLD), Child Pugh (CP), hazard ratio (HR), alcoholic liver disease (ALD), non-alcoholic steatohepatitis (NASH), transarterial chemoembolization (TACE), radiofrequency ablation (RFA), natural killer cells (NK cells), angiopoietin-2 (Ang-2), basic fibroblast growth factor (BFGF), vascular endothelial growth factor receptor (VEGFR), hepatocyte growth factor (HGF), soluble receptor c-KIT (S-C-KIT), insulin-like growth factor (IGF-1), high mobility group box 1 (HMGB1).

\section{CONFLICTS OF INTEREST}

No conflicts of interest to declare.

\section{REFERENCES}

1. El-Serag HB, Rudolph KL. Hepatocellular carcinoma: epidemiology and molecular carcinogenesis. Gastroenterology. 2007; 132:2557-2576.

2. Siegel R, Naishadham D, Jemal A. Cancer statistics, 2013. CA Cancer J Clin. 2013; 63:11-30.

3. Bruix J, Sherman M, and Practice Guidelines Committee, American Association for the Study of Liver Diseases. Practice Guidelines Committee, American Association for the Study of Liver Diseases. Management of hepatocellular carcinoma. Hepatology. 2005; 42:1208-36.

4. Llovet JM, Ricci S, Mazzaferro V, Hilgard P, Gane E, Blanc JF, de Oliveira AC, Santoro A, Raoul JL, Forner A, Schwartz M, Porta C, Zeuzem S, et al, and SHARP Investigators Study Group. Sorafenib in advanced hepatocellular carcinoma. N Engl J Med. 2008; 359:378-90.

5. Cheng AL, Kang YK, Chen Z, Tsao CJ, Qin S, Kim JS, Luo R, Feng J, Ye S, Yang TS, Xu J, Sun Y, Liang H, et al. Efficacy and safety of sorafenib in patients in the AsiaPacific region with advanced hepatocellular carcinoma: a phase III randomised, double-blind, placebo-controlled trial. Lancet Oncol. 2009; 10:25-34. 
6. Wilhelm SM, Carter C, Tang L, Wilkie D, McNabola A, Rong H, Chen C, Zhang X, Vincent P, McHugh M, Cao Y, Shujath J, Gawlak S, et al. BAY 43-9006 exhibits broad spectrum oral antitumor activity and targets the RAF/MEK/ ERK pathway and receptor tyrosine kinases involved in tumor progression and angiogenesis. Cancer Res. 2004; 64:7099-109.

7. Keating GM, Santoro A. Sorafenib: a review of its use in advanced hepatocellular carcinoma. Drugs. 2009; 69:223-40.

8. Sacco R, Mismas V, Romano A, Bertini M, Bertoni M, Federici G, Metrangolo S, Parisi G, Tumino E, Bresci G, Giacomelli L, Marceglia S, Bargellini I. Assessment of clinical and radiological response to sorafenib in hepatocellular carcinoma patients. World J Hepatol. 2015; 7:33-39.

9. Huan HB, Lau WY, Xia F, Ma KS, Bie P. Complete response to sorafenib in a patient with recurrent hepatocellular carcinoma. World J Gastroenterol. 2014; 20:14505-14509.

10. Miyahara K, Nouso K, Tomoda T, Kobayashi S, Hagihara H, Kuwaki K, Toshimori J, Onishi H, Ikeda F, Miyake Y, Nakamura S, Shiraha H, Takaki A, Yamamoto K. Predicting the treatment effect of sorafenib using serum angiogenesis markers in patients with hepatocellular carcinoma. J Gastroenterol Hepatol. 2011; 26:1604-1611.

11. Mantovani A, Allavena P, Sica A, Balkwill F. Cancer-related inflammation. Nature. 2008; 454:436-444.

12. Hoshida Y, Villanueva A, Kobayashi M, Peix J, Chiang DY, Camargo A, Gupta S, Moore J, Wrobel MJ, Lerner J, Reich $\mathrm{M}$, Chan JA, Glickman JN, et al. Gene expression in fixed tissues and outcome in hepatocellular carcinoma. N Engl J Med. 2008; 359:1995-2004.

13. Templeton AJ, McNamara MG, Šeruga B, Vera-Badillo FE, Aneja P, Ocaña A, Leibowitz-Amit R, Sonpavde G, Knox JJ, Tran B, Tannock IF, Amir E. Prognostic role of neutrophil-to-lymphocyte ratio in solid tumors: a systematic review and meta-analysis. J Natl Cancer Inst. 2014; 106:dju124.

14. Xiao WK, Chen D, Li SQ, Fu SJ, Peng BG, Liang LJ. Prognostic significance of neutrophil-lymphocyte ratio in hepatocellular carcinoma: a meta-analysis. BMC Cancer. 2014; $14: 117$.

15. Xue TC, Zhang L, Xie XY, Ge NL, Li LX, Zhang BH, Ye SL, Ren ZG. Prognostic significance of the neutrophil-tolymphocyte ratio in primary liver cancer: a meta-analysis. PLoS One. 2014; 9:e96072.

16. Qi X, Li J, Deng H, Li H, Su C, Guo X. Neutrophilto-lymphocyte ratio for the prognostic assessment of hepatocellular carcinoma: A systematic review and metaanalysis of observational studies. Oncotarget. 2016; 7:45283-301. https://doi.org/10.18632/oncotarget.9942.

17. Zheng YB, Zhao W, Liu B, Lu LG, He X, Huang JW, Li Y, Hu BS. The blood neutrophil-to-lymphocyte ratio predicts survival in patients with advanced hepatocellular carcinoma receiving sorafenib. Asian Pac J Cancer Prev. 2013; 14:5527-31.

18. da Fonseca LG, Barroso-Sousa R, Bento AS, Blanco BP, Valente GL, Pfiffer TE, Hoff PM, Sabbaga J. Pre-treatment neutrophil-to-lymphocyte ratio affects survival in patients with advanced hepatocellular carcinoma treated with sorafenib. Med Oncol. 2014; 31:264.

19. Alpert ME, Uriel J, de Nechaud B. Alpha-1 fetoglobulin in the diagnosis of human hepatoma. N Engl J Med. 1968; 278:984-6.

20. Mizejewski GJ. Biological role of alpha-fetoprotein in cancer: prospects for anticancer therapy. Expert Rev Anticancer Ther. 2002; 2:709-35.

21. Peng SY, Chen WJ, Lai PL, Jeng YM, Sheu JC, Hsu HC. High alpha-fetoprotein level correlates with high stage, early recurrence and poor prognosis of hepatocellular carcinoma: significance of hepatitis virus infection, age, p53 and beta-catenin mutations. Int J Cancer. 2004; 112:44-50.

22. Furihata T, Sawada T, Kita J, Iso Y, Kato M, Rokkaku K, Shimoda M, Kubota K. Serum alpha-fetoprotein level per tumor volume reflects prognosis in patients with hepatocellular carcinoma after curative hepatectomy. Hepatogastroenterology. 2008; 55:1705-9.

23. Merani S, Majno P, Kneteman NM, Berney T, Morel $\mathrm{P}$, Mentha G, Toso C. The impact of waiting list alphafetoprotein changes on the outcome of liver transplant for hepatocellular carcinoma. J Hepatol. 2011; 55:814-9.

24. Zhang Q, Shang L, Zang Y, Chen X, Zhang L, Wang Y, Wang L, Liu Y, Mao S, Shen Z. $\alpha$-Fetoprotein is a potential survival predictor in hepatocellular carcinoma patients with hepatitis B selected for liver transplantation. Eur J Gastroenterol Hepatol. 2014; 26:544-52.

25. Meguro M, Mizuguchi T, Nishidate T, Okita K, Ishii M, Ota S, Ueki T, Akizuki E, Hirata K. Prognostic roles of preoperative $\alpha$-fetoprotein and des- $\gamma$-carboxy prothrombin in hepatocellular carcinoma patients. World J Gastroenterol. 2015; 21:4933-45.

26. Carr BI, Buch SC, Kondragunta V, Pancoska P, Branch RA. Tumor and liver determinants of prognosis in unresectable hepatocellular carcinoma: a case cohort study. J Gastroenterol Hepatol. 2008; 23:1259-66.

27. Carr BI, Pancoska P, Branch RA. Low alpha-fetoprotein hepatocellular carcinoma. J Gastroenterol Hepatol. 2010; 25:1543-9.

28. Casadei Gardini A, Scarpi E, Faloppi L, Scartozzi M, Silvestris N, Santini D, de Stefano G, Marisi G, Negri FV, Foschi FG, Valgiusti M, Ercolani G, Frassineti GL. Immune inflammation indicators and implication for immune modulation strategies in advanced hepatocellular carcinoma patients receiving sorafenib. Oncotarget. 2016; 7:67142-49. https://doi.org/10.18632/oncotarget.11565.

29. Howell J, Pinato DJ, Ramaswami R, Arizumi T, Ferrari C, Gibbin A, Burlone ME, Guaschino G, Toniutto P, Black J, Sellers L, Kudo M, Pirisi M, Sharma R. Integration of 
the cancer-related inflammatory response as a stratifying biomarker of survival in hepatocellular carcinoma treated with sorafenib. Oncotarget. 2017; 8:36161-70. https://doi. org/10.18632/oncotarget.15322.

30. Personeni N, Giordano L, Abbadessa G, Porta C, Borbath I, Daniele B, Van Laethem JL, Van Vlierberghe H, Trojan J, De Toni EN, Gasbarrini A, Lencioni M, Lamar ME, et al. Prognostic value of the neutrophil-to-lymphocyte ratio in the ARQ 197-215 second-line study for advanced hepatocellular carcinoma. Oncotarget. 2017; 8:14408-15. https://doi.org/10.18632/oncotarget.14797.

31. Bruix J, Cheng AL, Meinhardt G, Nakajima K, De Sanctis Y, Llovet J. Prognostic Factors and Predictors of Sorafenib Benefit in Patients With Hepatocellular Carcinoma: Analysis of Two Phase 3 Studies. J Hepatol. 2017; 67:999-1008. https://doi.org/10.1016/j.jhep.2017.06.026.

32. Vujanovic L, Stahl EC, Pardee AD, Geller DA, Tsung A, Watkins SC, Gibson GA, Storkus WJ, Butterfield LH. Tumor-Derived $\alpha$-Fetoprotein Directly Drives Human Natural Killer-Cell Activation and Subsequent Cell Death. Cancer Immunol Res. 2017; 5:493-502.

33. Yamamoto M, Tatsumi T, Miyagi T, Tsunematsu H, Aketa H, Hosui A, Kanto T, Hiramatsu N, Hayashi N, Takehara T. $\alpha$-Fetoprotein impairs activation of natural killer cells by inhibiting the function of dendritic cells. Clin Exp Immunol. 2011; 165:211-9.
34. Harimoto H, Shimizu M, Nakagawa Y, Nakatsuka K, Wakabayashi A, Sakamoto C, Takahashi H. Inactivation of tumor-specific $\mathrm{CD}^{+}$CTLs by tumor-infiltrating tolerogenic dendritic cells. Immunol Cell Biol. 2013; 91:545-55.

35. Pardee AD, Shi J, Butterfield LH. Tumor-derived $\alpha$-fetoprotein impairs the differentiation and $\mathrm{T}$ cell stimulatory activity of human dendritic cells. J Immunol. 2014; 193:5723-32.

36. Llovet JM, Peña CE, Lathia CD, Shan M, Meinhardt G, Bruix J, and SHARP Investigators Study Group. Plasma biomarkers as predictors of outcome in patients with advanced hepatocellular carcinoma. Clin Cancer Res. 2012; 18:2290-300.

37. Masuda K, Ono A, Aikata H, Kawaoka T, Nelson Hayes C, Teraoka Y, Daijo K, Nakamura-Inagaki Y, Morio K, Fujino H, Kan H, Uchida T, Masaki K, et al. Serum HMGB1 concentrations at 4 weeks is a useful predictor of extreme poor prognosis for advanced hepatocellular carcinoma treated with sorafenib and hepatic arterial infusion chemotherapy. J Gastroenterol. 2018; 53:107-18. 